\title{
Linguistic Features of Political Discourse
}

\section{Kuralay Kenzhekankyzy Kenzhekanova}

\author{
Al-Farabi Kazakh National University, al-Farabi ave., 71, Almaty, 050038, Kazakhstan
}

\section{Doi:10.5901/mjss.2015.v6n6s2p192}

\begin{abstract}
The article deal with discourse, in particular with political discourse. Various interpretations of political discourse are discussed in the article. Two big groups of discourse such as personal-oriented and institutional-oriented are described from different point of views offered by various scientist. Features of political discourse are given and supported by a number of examples. From a pragmatic point of view the following linguistic features of political discourse are analyzed: the image of the author, informational content, the factor of addressee, intentionality, estimation, conventionality, emotiveness, modality, intertextuality, social-cultural content, ideological characters, form and means of communication. Specific characteristics of a political discourse such as competitiveness, aggressiveness, ideological character and theatricality are studied as well. All above mentioned characteristics and linguistic features formulate political discourse and contribute its pragmatics in terms of influence on mass consciousness.
\end{abstract}

Keywords: discourse, political discourse, linguistic features, categories, pragmatics, influence, mass media, communication, addressee.

\section{Introduction}

Discourse, on the one hand, can be considered as the process of real-life verbal communication in which an important role is paid to the following things such as systemic characteristics of language, the degree of spontaneity and completeness, thematic coherence and clarity for other people. But, on the other hand, it is impossible to forget that communication of people always proceeds in this or that dependence on the position of communicants. Here it's important that they belong to a social group and a typical speech situation.

Discourse incorporates and reflects the unique set of circumstances, at which and for which it was created: 1) communicative intentions of the author; 2) relationship between the author and addressees; 3) all kinds of circumstances, "significant" and casual; 4) ideology and stylistic climate of an era in general, the concrete environment, specific individuals to whom the message is addressed; 5) genre and stylistic features of message and communicative situation; 6) associations with the previous experience which got to an orbit of the speech act (Karasik, 2002).

Certain types of a discourse are allocated by taking into account these factors and circumstances, accompanying statements, as well as their combination with the appropriate linguistic means.

\section{Literature Review}

\subsection{Discourse and its interpretations}

Many scholars have identified, on the one hand, national discourses (such as Kazakh, English, French, etc.), on the other - such types as a poetic, scientific, political, economic, pedagogical. The main condition for the existence of the second classification is that all these types of discourse are allocated within one of the national discourse. They "are not certain types of discourse, but only some "modification" of the latter, in a certain way, "adapted" in accordance with the sphere in which it functions" (Krasnyh, 1999).

Nevertheless, the bigger number of scientists is tend to speak about types of a discourse, without affecting classification by criterion of a national identity. They highlight practical types of a discourse which are used widely in ideological, cultural, historical and communicative situations, and therefore can be studied from a position of the general theory of communication: scientific, political, pedagogical, critical, legal, general, private, etc.

Scientist D.A. Alkebayeva claims that "discourse is a main form of communication. It's right to rely on communication between the addresser and addressee of discourse which leads to appearance of new branch called pragma-stylistics. It deals with two aspects of communication: oral - discourse and written - text. Discourse takes into account verbal and non-verbal linguistic means, mental issues, intention of communicants as well as communication 
tools" (Alkebayeva, 2014). Here we see that discourse is identified as an oral form of communication and it's a concern of pragmatics which has a definite purpose in order to influence on the addressee using different methods.

The basis of classification of discourse offered by V.I. Karasik, is the criterion of orientation. He identifies two main types of discourse: 1) personal (personal-oriented) in which the speaker acts as the individual in all richness of his inner world; 2) institutional (status-oriented) in which the speaker acts as the representative of a certain social status (Karasik, 2000).

Similar division of a discourse on personal and institutional is also supported in works of P. Grays, J. Austen, J. Searle, D. Gordon, J. Lakoff, N. I. Formanovskaya, V. S. Kubryakova.

The criterion of classification of a discourse according to Matveeva sounds simple: classification is based on the concepts of the addresser and addressee.

The first type of a discourse means communication in the form of monologue and desire to come to the reduced type of communication at a close distance. The second type is a communication within the status and role relations, i.e. speech interaction of representatives of social groups with each other.

The institutional discourse represents communication within the status and role relations. In relation to modern society the following types of an institutional discourse are allocated: political, diplomatic, administrative, legal, military, pedagogical, religious, mystical, medical, business, advertizing, sports, scientific, scenic and mass-informational (Karasik, 2000).

V.I. Karasik emphasizes that this list isn't strictly fixed, it can both be changed, and expanded as public institutes significantly differ from each other and can't be considered as the homogeneous phenomena; they are historically changeable, they can merge with each other and arise as versions within this or that type.

It is important to understand that all listed types of a discourse make only a small share from their available huge number. Taking number of public institutes as a basis, it is possible to speak about the discursive practices of each of these areas. Thus, the fact that any of these discourses will possess own specifics, isn't even called into question. Speaking about specifics, we mean existence of characteristic features.

\subsection{Classification of a political discourse}

In this article, we refer to the consideration of the characteristic features and signs of political discourse, but before proceeding to the immediate consideration of its content, it makes sense to bring the definition of the term "political discourse".

Taking into account the definitions of political discourse given by various authors (Baranov and Kazakevich, 1991; Demyankov, 2002; Parshin, 1999; Pocheptsov, 2000; Chudinov, 2007; Shahovskii, 1998; Sheygal, 2004 and etc.), we offer the following definition of this concept: political discourse is a collection of all speech acts, as well as public law, tradition and experience, which is determined and expressed in the form of verbal formations, content, subject and the addressee of which belongs to the sphere of politics.

Referring political discourse to the type of institutional communication, we, first of all, propose to consider the specifics of its discursive content. Specifics of institutional discourse is revealed in its type, i.e. in the type of public institution, which is identified by a special name in the collective consciousness of the language and generalized in the key concepts of this institution, in particular, functioning of political discourse as a power (Karasik, 2000). Consequently, the political discourse is not just a communication; it brings together its clear goals and specific participants. The purpose and a choice of participants depend on the particular type of a discourse, so in this case the purpose of political discourse is the conquest and deduction of power; and its participants are politicians and society.

Under the content of political discourse we suggest to understand a set of all essential features of a political discourse that are common to all genres of this discourse and can distinguish it from other types of a discourse. Building a comprehensive and accurate system of distinctive features is rather complicated, as they form a very agile frame, features of which depend on the type and specificity of a concrete discourse.

Taking into account the classification of various authors (Alekseeva, 2001; Karasik, 2004; Konkov, 2011; Hlevova, 1999) we suggest highlighting the most common semantic-pragmatic categories, i.e. inherited features as part of the political discourse:

1) The image of the author

As a rule, this category is important in characterizing both personal-oriented and status-oriented discourse. Depending on a communication situation the image of the author consists of the following components:

a) the author's abstraction when his personal characteristics and psychological states have no communicative priority; 
b) the author's personification when personal characteristics of the interlocutor and his psychological state considerably influence on communication process;

Concepts of objectivity and subjectivity correspond to these two situational characteristics.

The second component of this category - personification - is peculiar to a political discourse and consequently, subjectivity as well. The addressers use their own personal and professional experience, show author's identity both in selection of factual material, and language means of its organization in the course of political debate and exchange of information about political events and decisions;

c) style of a statement;

d) para-textual components (photo of the author, a brief information about author, the image of the author).

e.g. Barack Obama's Vision for the Future:

"I believe that the single most important job of any President is to protect the American people. And I am equally convinced that doing that job effectively in the 21st century will require a new vision of American leadership and a new conception of our national security - a vision that draws from the lessons of the past, but is not bound by outdated thinking"(Barack Obama, 2008).

2) addressee ability or factor of addressee

The structure of a discourse assumes existence of two roles: the speaker's and the addressee's therefore on the course of the analysis of a discourse it is possible to recreate the mental world of communicants, details and an assessment of reality from two points of view, from the point of view of creation of a discourse and from a position of its understanding. Therefore, the addressee ability as a category of a discourse is one of priority. Creating a specific text assumes the removal of some abstract models of the addressee having a complex of features that can ensure the normal perception of the message. Of course, the person conducting the construction of discourse has a privileged position, which is often used, imposing their views to the addressee. This circumstance plays an important role especially in the sphere of policy, in other words in the world of rulers of fate, and also closely connects this category with the following concepts:

a) communicative leadership (in the situation of communication the communicative leader will be the one who regulates the process of communication by directing it to the achievement of the communicative objects);

b) communicative equality (in the situation of communication it is possible to speak about equality of interlocutors if allocation of the leader looks formal or non-existent).

In political communication it is possible to find both the first, and second type of an addressee ability depending on a genre of a political discourse, for example, to genres of political interview, the political document (the decree of the president, the text of the law), and etc. are more peculiar the type of communicative leadership, while to polemic genres televised debates, discussion - are peculiar the type of communicative equality. The genre of pre-election race is offered to take out separately as the genre connecting both of these concepts of the category of addressee ability depending on the one who the addressee is for the speaker at the moment - directly the opponent, i.e. the equal rival or the audience (live and TV viewers), i.e. the third party. According to their opinion there is a requirement to have impact.

3) Informational content

This category to a greater or lesser extent characterizes any act of communication, but nevertheless directly depends on the communicative purposes of a discourse. The purpose of a political discourse and its social mission is suggestion of the need of politically correct actions to addressees.

4) Intentionality

It is a category of a discourse which means communicative intention of the speaker. Any verbal work (from word to text) is said by the author with this or that intention. This category in relation to political discourse, as well as the previous one, is in direct dependence on the discourse purpose which already dictates rules of verbal behavior to the addressee. The purpose of a political discourse can not only be the suggestion of the need of actions to addressees, but also estimation. The following category of a political discourse is connected with the last component.

\section{5) Estimation}

The task while creating a political discourse is not set to objectively describe reality but to emphasize certain features of this phenomenon by convincing the recipient, prompting him to some action desired for the creator of a discourse in certain circumstances. Consequently, the formation is performed in a certain society to the political event and its evaluation, which is necessary for this subject, is carried out. For this purpose, in the political discourse the speaker can use axiological (estimated) vocabulary, which is a kind of center of gravity, which emphasizes the attention and influences on the consciousness of the reader. 


\section{6) Conventionality}

This category is called as interpretability (Karasik, 2000) or perceptual-ability (Komarov, 2003) by some authors. We suggest to take broader concept of conventionality which helps to simplify schemes of interpretation of realias. Conventionality will have three forms of manifestation:

a) cliché (i.e. clarity and accuracy of information, logicality and simplicity of a statement; cliché and stamps are used in order to cause the existing stereotypes in consciousness of the listeners, to make information concise and much more easier to understand);

e.g. last but not least, boom and bust, apart from the fact that, in the absence of, to the extent that, by the same token, to take / hold the view that, strictly speaking, to proceed from the assumption that, to sum up the above-said, to bear in mind.

b) being terminological (i.e. the presence of terminological apparatus that meets all the requirements: accuracy of meaning, briefness, linguistic correctness, the entry into the system, the use of terminological definitions contributes to the creation of more complex, branched definitions of terms and makes it possible to saturate them with new connotations)

e.g. to corroborate a statement, proponents, a vision, heterogeneous, soft power - soft influence, i.e. influence through culture, ideology and propaganda; hard power - hard influence, i.e. pressure exerted by military and economical levels; coalition of the willing - coalition of voluntary partner; managed democracy, velvet revolution, velvet divorce; Europhobia - fear of European integration, a negative attitude towards the EU; Eurosceptic - the enemy of European integration; Europhilia - an enthusiasm for European integration and a positive attitude towards the European Union.

Politicians and political scientist make a great contribution in formulation and creating new terms in politics.

E.g. dark horse - politician not known to be a candidate who, at a deadlocked convention, unexpectedly receives the nomination. This term derives from racing slang for a little-known horse that unexpectedly goes to the front (Dickson, 2013).

Axis off evil - coined by speechwriter David Frum for Geaorge W. Bush in his 2002 State of the Union address. Bush used it to describe governments he accused of helping encourage terrorism and weapons of mass destruction. In his autobiography, Decision Points, Bush wrote, "In my state of the Union address, I had outlined the threats posed by Iraq, Iran, and North Korea. States like these, and their terrorist allies, constitute an axis of evil, arming to threaten the peace of the world. The media seized on the phrase 'axis of evil'. They took the line to mean that the three countries had formed an alliance. That missed the point. The axis I referred to was the link between the governments that pursued WMD and terrorists who could use those weapons/ There was a larger point in the speech that no one could miss: I was serious about dealing with Iraq" (Dickson, 2013).

Window of vulnerability is coined by Ronald Reagan to refer to the moment in time when he felt the Soviet Union would be able to wipe out U.S. nuclear weapons capabilities in a single preemptive first strike attack (Dickson, 2013).

Obamacare - a term of derogation for Barack Obama's Patient Protection and Affordable Care Act., which was proposed by the democratic leadership and became law in March 2010 (Dickson, 2013).

c) rituality (i.e. stereotyping of behavior).

e.g. None of us - black, white, Latino, or Asian is immune to the stereotypes that our culture continues to feed us, especially stereotypes about black criminality, black intelligence, or the black work ethic. In general, members of every minority group continue to be measured largely by the degree of our assimilation - how closely speech patterns, dress, or demeanor conform to the dominant white culture - and the more that a minority strays from these external markers, the more he or she is subject to negative assumptions. (Dickson, 2013).

It's necessary to give statement concerning clichés and speech stereotypes claimed by professor D.A. Alkebayeva who states that "the difference between clichés and speech stereotypes can be observed in meta-text (target-text), which is a necessary condition for communication. It means the transformation of speech signals by the addresser and the addressee directly or indirectly, consciously or unconsciously, explicitly or implicitly" (Alkebayeva, 2014).

7) Emotiveness / expressivity

The basis of this category is made by various combinations of syntactic elements which give to concrete discourses and texts, as productive embodiments of discourses, not only integrity and connectivity, but also an additional expression. In a political discourse expressional shades depending on the purpose of their use for giving these or those semantic characteristics can vary from friendly familiar to slightly sarcastic, so that standard canons of institutional, i.e. official etiquette of formulations are quite often broken. According to A.Yu. Mazayev, the discourse of politician has 
always brightly colored by emotional character as the purpose of such performances is to convince the listeners that imply certain language features of a political discourse (Mazayev, 2005).

Existence of emotiveness in a political discourse also varies from genre to genre. For example, it is difficult to present the emotional features in decrees, laws or informative notes and analytical articles, while emotiveness for public political speech (e.g., the inaugural address, or the farewell speech of the president), polemics and interviews with politicians is an integral component. The percentage of emotiveness in political discourse does not depend only on the choice of the genre, but also on the specific discursive events or subjects. So, if to take parliamentary speeches as an example, the category of informational content will obviously prevail over the category of emotiveness. Informational content will prevail in case of routine legislative activity, in contrast to those cases where "hot" political issues, such as approval or withdrawal of a candidate on or from the state post or discussions about the conduct or failure to conduct new reforms and etc are on the agenda. In the latter case, agonistic function of political discourse moves to the forefront and the informational content gives way to expressivity.

e.g. Speech of President of the USA, Barack Obama:

"We need not look to the past for greatness, because it is before our very eyes. This generation of soldiers ...have served tour after tour of duty in distant, different and difficult places. They have stood watch in blinding deserts and on snowy mountains...They are man and woman; white, black, and brown; of all faiths and stations - all Americans, serving together to protect our people, while giving others half a world away the chance to lead a better life" (Pine, 2009).

\section{8) Modality}

The category of a modality is understood as the attitude towards reality in the representation of the speaker. Speaker's evaluations of the content of expressions in terms of reality / unreality, possibility, necessity or desirability, the degree of certainty of the reported thing, qualitative estimation of the content of statements are characteristics that are applicable not only to the participants of the discourse, but to the discourse as a whole.

Expressions of the need and desirability are implemented in the component of modality, which can be described as prescriptive (a reasonable expression of prescriptions). In another aspect, modality also implies a degree of confidence of the speaker that will demonstrate the level of knowledge, from which the seriousness of the impression produced by political performance of the addressee will be depended on.

e.g. "America is the country that helped liberate a continent from the march of a madman. We are the country that told the brave people of a divided city that we were Berliners too. We sent generations of young people to serve as ambassadors for peace in countries all over the world. And we're the country that rushed aid throughout Asia for the victims of a devastated tsunami.

Now it's our moment to lead - our generation's time to tell another great American story. So some day we can tell our children that this was the time when we helped forge peace in the Middle East. That this was the time when we confronted climate change and secured the weapons that could destroy the human race. This was the time when we brought opportunity to those forgotten corners of the world. And this was the time when we renewed the America that has led generations of weary travelers from all over the world to find opportunity, and liberty, and hope on our doorstep"(Barack Obama, 2007).

Here the use of we/ our adds to the speech of Baraka Obama coloring and makes his speech much more rich and touches everyone's heart deeply so that it can reach its purpose.

9) Inter-textuality

The relationships between public and linguistic structures which are realized in the universal text, a set of the general and specific features of texts, the process of continuous absorption and transformation, creation and reinterpretation of the text, inclusion of other texts or its elements - all these imply manifestation of category of intertextuality. The category of inter-textuality is mostly peculiar to literary discourse. However any life (social or spiritual) assumes existence of at least two consciousnesses, two texts which are crossed with each other to full absorption of one in another so that each of them is a total context of another, the guarantor of its existence. Thus, all this means that separate elements of various discourses can interpenetrate each other creating a certain semantic loading. Considering this fact, we consider logical to consolidate category of inter-textuality as the sign peculiar to each type of a discourse. Thus, the inter-textuality acts as the universal principle of construction and the political text at the level of content.

10) Socio-cultural context

This category represents ability to activate and involve the complex of socio-cultural contexts (knowledge) of recipients (Filonenko, 2005) in the process of perception. Understanding the political oral and written texts depends on 
the ability of the reader to instantly identify the subject, the subject matter and to involve allusions that are needed to understand the content.

All above-mentioned semantic-pragmatic categories, which are present at the text, are typical indicators of texts within a political discourse. Therefore, in the analysis of a political discourse linguists should take into account both extralinguistic factors (the circumstance accompanying the events described in the text, the background that explains these events and estimation of participants of an event), and linguistic factors as well (a phonetic system of the text, grammatical, lexical features of the text).

Having listed the main semantic and situational features of a political discourse, it is necessary to tell about its communicative and functional features, exactly:

11) Form of communication

12) Means of communication

If the last category is presented by two components: verbal/nonverbal means of communication, whereas forms of communication are presented by four types:

- depending on the method of information transfer: oral / written;

- depending on the number of participants of communication: polylogue / dialogue.

Thus poly-logicality is characterized by features of versatility and a poly-orientation of composition (Alekseeva, 2001). Political discourse is characterized by poly-logical form of communication, i.e. the special multilateral mediated form of speech communication, structural and compositional address to several interlocutors and polyphony of various authors. Thus, all these 12 main discursive features will be components of the content of a political discourse. Despite of their features of functioning within a political discourse described by us above, these features can be found in the content structure and other types of a discourse, and, therefore, serve as a basis for comparison and the opposition of different types of discourse.

\subsection{Main features of a political discourse}

But it is necessary to mention about the individual or specific features that are unique only to this concrete type of a discourse, for example, specific feature of poetic discourse are the substantiality and otherness (the special mechanism of reproduction, the most important phenomenological and genetic principle of poetry).

Specific characteristics of a political discourse are the following 4 features: 1) agonistic ability; 2) aggressiveness; 3) ideological character; 4) theatricality.

1) Agonistic ability, i.e. competitiveness

The basis of a political discourse is made by continuous dialogue duel between the party in power and opposition in which opponents attack at each other from time to time, hold the fort, reflect blows and take the offensive. Convergence of political discourse on this feature with sports discourse is shown in the reflection of all the basic elements of sports and gaming competition in the sphere of politics: the presence of the enemy, fight of rivals, ethics of fight, legal regulations (rules and regulations), the strategy and tactics of fight, victory, defeat, triumph of the winner, winning. The competitiveness of a political discourse with the greatest evidence is shown in such forms, as parliamentary debates and the pre-election companies.

2) Aggressiveness

One of the most important components of a political speech is aggression. In English explanatory dictionaries the word "aggression" is defined as "violent or hostile feelings, behavior or attitude" (Oxford, 2000). Thesaurus list of this word is one of the most numerous: antagonism, assault, attack, bellicosity, belligerence, combativeness, destructiveness, encroachment, hostility, impingement, incursion, injury, intrusion, invasion, jingoism, militancy, offense, onslaught, provocation, pugnacity, raid, etc. (Wordsworth,1993).

Aggression in a political discourse is also connected with concept of hierarchy and domination. Hierarchy from Greek word "hieros" means sacred and "arche" stands for the power; the relations of subordination, the chain of commands, the chain of commands of the lowest to the highest, and domination from Latin word "dominantis" means dominating; aspiration to domination, prevalence and leadership. Aggression is considered as a basis of domination which in turn is a consequence of aggression and defines a hierarchical order of the human relations.

The reason of hierarchy is the competition connected with struggle for power, a social status and recognition, strengthening territorial positions or positions in collective, etc. If to consider speech aggression in the framework of political communication, it should be noted that here the dominant aggression is directed at a concrete political figure that isn't presented in the situation of communication, i.e. the critic of the political opponent "for eyes" in dealing with the third party or mass audience in public speeches, interview or political discussions. 
Verbal aggression is presented by specific speech acts. Highlighting speech acts of aggression, it should be noted that all of them are demonstration of political force and directed to downgrade the status of the addressee. Standard speech acts of aggression in a political discourse are allocated:

- $\quad$ expressive wills with semantics of exile (acts of will);

- categorical requirements and appeals;

- $\quad$ speech acts of a damnation (in slogan genres);

- $\quad$ speech acts of threat (Sheygal, 2004).

3) Ideological character

The ideological character represents the system of social representations, group knowledge, beliefs and opinions based on group values, norms and interests. This feature brings the political discourse with the military. War, as we know, is continuation of policy by other means. The scope of their interaction is such genres as military doctrine, military and political agreement, an ultimatum, peace negotiations, i.e. genres, providing the ideology and course of the war from the perspective of the warring parties.

\section{4) Theatricality}

The category of theatricality pulls together a political discourse with advertizing and scenic discourses. Theatricality of a political discourse is connected with the fact that one of the parties of communication - the people - carries out not a role of the direct addressee, but the observer addressee who perceives the current political events as the certain performance played for them with a fascinating plot and the unpredictable end. Politicians, communicating with each other and with journalists, constantly remember about "a spectator audience" and intentionally or unintentionally act or "work for public", trying to make impression and "to break an applause". Political "theatre" is based on images of politicians. If a plot-role component of political discourse is referred mainly in the figurative sense, its "director's" component appears directly in a number of political events in which element of performance (there are a script and prewritten texts, distribution of roles, rehearsals) is essential.

e.g. If fate had put Gore and Bush in the other's place on election night, the drama of the next five weeks would have had everybody playing the opposite role. This election is not an award for past performance, Congressional Digest, October 2000.

We celebrate the peaceful transition of power in a democracy; and then we sit back and judge how the players perform - how graceful the losers, how gracious the winners, a fierce pageant of patriotism and pride and prejudice all tightly staged on the Capitol, Time.

Hearings serve as a kind of overture to the First act of a new President, a preview of all the themes and characters that will share the stage and shape the combat for the next four years, Time.

First of all, the genre of political advertizing is absolutely dramatized. The political type of advertizing is directed on formation of certain "image" of the public figure or organization and motivation to a certain line of conduct in relation to them. Both are used in political advertising and implemented in the genres of political propaganda (posters, presentations, public speeches, debates) and agitation (appeals, leaflets, banners, speeches at meetings). Secondly, these ritual events have the character of a mass spectacle, for example, the inauguration or actions devoted to national holidays.

Besides ritual events which occur regardless of mass media and only lit in mass media, there are so-called pseudo-events which include specially planned events for the purpose of their immediate display or transmission of information about them. Interview, a press conference, television conversation, television discussion, television debates and so forth belong to the category of pseudo-events. All these discursive versions are communicative events which dramatic art is substantially set by mass media, although their substantial part is mainly spontaneous.

\section{Conclusion}

Thus, the field approach to the analysis of semantic-pragmatic structure of a political discourse allows to reveal not only all specific features of this type of discourse, but also spheres of its contact with other types of discourse to some extent. Due to its goal the field system of the discursive features can help to identify features which are in and out of a zone of crossing of different types of discourse and also to confirm closer interdependence of types of a discourse within each class allocated according to the status characteristics.

The information in the political discourse of mass media is the interpretation, which is a phenomenon quite different than, for example, an event that cannot be objective. The human factor plays a special role in any kind of discourse. Discourse is an anthropocentric phenomenon, it reflects the world subjectively, as speaker (writer) "assigns" speech due 
to its evaluative feature. Due to the fact that the subject of political discourse of mass media, which reflects some of the interests and has some goals and objectives, interprets reality in the text, this kind of discourse is differentiated by subjectivity, which contributes to the manipulation of information in the desired direction for the addressee.

Due to the above-mentioned views, we can say for sure that the political discourse of mass media appears as the independent communicative phenomenon formed in the sphere of interaction of a political discourse and a discourse of mass media. Such features as the intentionality, mass orientation, national and cultural specificity, an ideological feature, informational content, subjectivity, aggressiveness, competiveness, agonistic ability, theatricality, emotiveness, modality, intertextuality, the factor of addressee and conventionality create necessary prerequisites for manipulation of public consciousness. Thereby the political discourse of mass media possesses all the capabilities to manage the views and attitudes of the audience in the necessary sphere for the subject.

\section{References}

Alekseeva, M. V (2001). Scientific text as polylogue (Monograph). Moscow: Signal.

Alkebayeva, D.A. (2014). Pragma-stylistics of the Kazakh language. Almaty: Kazakh University

Baranov, A.N., Kazakevich, E. G. (1991). Parliamentary debates: traditions and innovations, Modern political language (from ritual to metaphor (pp.63-70). Moscow: Znanie.

Barack Obama: $44^{\text {th }}$ President of the Unites States.(2008). Washington.

Barack Obama addresses the Chicago Council on Global Affairs. (April 23, 2007). Retrieved from April 23, 2007, from https://my.barack obama.com/page/content/fpccgal

Demyankov, V.Z. (2002). Political discourse as subject of political philology, Political science. Political discourse: History and modern researches (pp.32-43). Moscow: INION of the Russian Academy of Sciences.

Dickson P. (2013). Words from the White House. New York.

Chudinov A. P. (2007). Politcal linguistics: manual (2nd edition). Moscow: Flint: Science.

Filonenko, T. A. (2005). Genre and stylistic characteristics of an English-speaking scientific and methodical discourse (abstract of a thesis of cand. Phil.sciences). Samara.

Hevova, Yu. A. (1999). Types of modal meanings. Bulletin of the Amur state university. Vol. 7. URL: http://www.amursu.ru/vestnik/7/9_ 7_99.html.

Karasik, V.V. (2004). Language circle: personality, concepts, discourse. Moscow, Gnosis.

Karasik, V.V. (2000). About types of discourse, Language personality: institutional and personal discourse (pp.5-20). Volgograd: Peremena.

Karasik, V. I. (2002). Language circle: personality, concept, discourse. Volgograd, Peremena.

Komarov, E. N. (2003). Value orientations in headings of French and Russian mass media (abstract of a thesis of candidate of phil. sciences). Volgograd.

Konkov, V.I. (2011). Speech structure of the newspaper text (abstract of a thesis of doctors of phil. sciences). St.-Petersburg.

Krasnyh, V. V. (1999). Structure of communication in the light of lingvo-cognitive approach: communicative act, discourse, text (diss. doctors of phil. sciences). Moscow.

Mazayev, A.Yu. (2005) Political discourse: factor of addressee. Retrieved 2005 from http://www.ostu.ru/conf/ruslang2005/trend1/ mazaeva.htm.

Oxford Advanced Learner's Dictionary (5th Ed). (2000). Oxford University Press.

Parshin, P. B. (1999). Concept of an idio-political discourse and methodological bases of political linguistics. Moscow.

Pine J. (2009) Wit and wisdom of American Presidents: a book of quotations, published by Dover publication. New York, Mineola.

Pocheptsov, G. G. (2000). Information wars. Moscow.

Shakhovsky V.I. (1998). Voice of emotions in the Russian political discourse, Political discourse in Russia. Moscow.

Sheygal, E. I. (2004). Semiotics of a political discourse. Moscow, Gnozis.

The Wordsworth Thesaurus (1993). Wordsworth Editions Ltd. 